\title{
Rancang Bangun Bandpass Filter Mikrostrip Metode Hairpin Pada Frekuensi 2.3 Ghz
}

\author{
Afif Orifansyah ${ }^{1, *}$, Wisnu Djatmiko ${ }^{2}$, dan Baso Maruddani ${ }^{3}$ \\ 1 Mahasiswa Prodi Pendidikan Teknik Elektronika, Fakultas Teknik - UNJ \\ 2,3 Dosen Prodi Pendidikan Teknik Elektronika, Fakultas Teknik - UNJ
}

\begin{abstract}
Abstrak. Penelitian ini bertujuan untuk merancang, menguji bandpass filter mikrostrip dengan metode hairpin pada frekuensi $(2,3 \mathrm{GHz}$ sampai dengan 2,4 GHz), dengan bandwidth $100 \mathrm{MHz}$. Penelitian dilaksanakan di Laboratorium Telekomunikasi Lantai 4 (Gedung L1) Universitas Negeri Jakarta, pada bulan Maret - Oktober 2016.Bandpass mikrostrip metode hairpin merupakan pengembangan bandpass mikrostrip edge coupled, Konsep Haipin filter memiliki panjang resonator $\lambda / 2$ yang terkopel secara paralel dan bentuk resonatornya seperti huruf ' $U$ '. Teknik ini merupakan pengembangan dari parallel couple dimana saluran couple line $\lambda / 4$ dilipat sebesar $\mathrm{L}$ atau $((\lambda / 4)-b)$, b adalah panjang saluran yang tidak mengalami kopling.Dari hasil penelitian bandpass filter hairpin dibuat dan diuji secara simulasi dengan hasil perhitungan kemudian simulasi menggunakan hasil fabrikasi dan pengukuran. Sehingga dapat disimpulkan bahwa bandpass filter hairpin ini berhasil didesain pada perangkat lunak CST Microwave Studio, difabrikasi, dan diuji menggunakan alat ukur network Analyzer dengan hasil parameter frekuensi cut off 2,355 GHz, bandwidth sebesar $106 \mathrm{MHz}$.
\end{abstract}

Kata kunci: fillter, bandpass filter mikrostrip, metode hairpin, 4G dan WIMAX

\begin{abstract}
This study aims to design and test the microstrip bandpass filter with the hairpin method at a frequency $(2.3 \mathrm{GHz}$ to $2.4 \mathrm{GHz})$, with a bandwidth of $100 \mathrm{MHz}$. The research was carried out at the 4th Floor Telecommunication Laboratory (L1 Building) of the State University of Jakarta, in March - October 2016. The hairpin method microstrip bandpass is the development of an edge coupled bandpass microstrip, the Haipin filter concept has a resonator length $\lambda / 2$ which is coupled in parallel and the shape of the resonator is like the letter ' $U$ '. This technique is the development of parallel couple where the $\lambda / 4$ couple line channel is folded by $L$ or $((\lambda / 4)-b), b$ is the length of the channel that is not coupled. From the research results the hairpin band pass filter is made and tested in a simulation with the results calculations are then simulated using the fabrication and measurement results. So it can be concluded that the hairpin bandpass filter was successfully designed in CST Microwave Studio software, fabricated, and tested using a network analyzer measuring instrument with a cut-off frequency parameter of $2.355 \mathrm{GHz}$ and a bandwidth of $106 \mathrm{MHz}$.
\end{abstract}

Keywords: fillter, bandpass microstrip filter, hairpin method, $4 G$ and WIMAX

\section{Pendahuluan \\ 1.1 Latar Belakang Masalah}

Menuntut para peneliti dibidang telekomunikasi, dibutuhkan teknologi untuk berkembang guna memenuhi kebutuhan masyarakat. Teknologi telekomunikasi yang sangat berkembang dibidang seluler antara lain 4G dan Wimax. Teknologi terbaru akan mendatangkan banyak keuntungan untuk akses kecepatan, namun perlu dukungan oleh perangkat perangkat lainnya.Alokasi frekuensi merupakan suatu hal yang sangat dibutuhkan dalam industri telekomunikasi. Terutama untuk komunikasi mobile, frekuensi menjadi sumber daya utama yang harus tersedia. Tetapi pentingnya alokasi frekuensi tersebut tidak didukung dengan jumlahnya yang sangat terbatas. Di Indonesia, hampir semua alokasi frekuensi untuk kebutuhan seluler telah digunakan untuk berbagai macam teknologi.

Berdasarkan Peraturan Menkominfo nomor 08/PER/M.KOMINFO/01/2009 tanggal 19 Januari 2009 tentang Penetapan Pita Frekuensi Radio Untuk Keperluan Layanan Pita Lebar Nirkabel Pada Pita Frekuensi Radio $2.3 \mathrm{GHz}$ ditetapkan bahwa pita ini menggunakan moda TDD (Time Division Duplex) yang terdiri dari 15 nomor blok dimana nomor blok1 sampai dengan nomor blok 12 masing-masing lebar frekuensinya $5 \mathrm{MHz}$ sedangkan nomor blok 13 dan nomor blok 14 masing-masing lebar frekuensinya $15 \mathrm{MHz}$ dan nomor blok 15 lebar frekuensinya $10 \mathrm{MHz}$. Pada blok 13 dan 14 ini telah digunakan untuk layanan WiMAX yang telah dilakukan tender untuk beberapa wilayah regional. penggunaan pita saluran frekuensi pada rentang $2.3 \mathrm{GHz}$ di tunjukkan pada tabel 1 
Table 1. aplikasi yang digunakan pada rentang frekuensi $2.3 \mathrm{GHz}$.

\begin{tabular}{|c|c|c|}
\hline NO & $\begin{array}{c}\text { RENTANG FRFKLENSI } \\
(\mathrm{MH}-\mathrm{z})\end{array}$ & LAYANAN \\
\hline 1 & $2300-2305$ & Broadband wireless access \\
\hline 2 & $2305-2310$ & Broadband wireless access \\
\hline 3 & $2310-2315$ & Broadband wireless access \\
\hline 4 & $2315-2320$ & Broadband wireless access \\
\hline 5 & $2320-2325$ & Broadband wireless access \\
\hline 6 & $2325-2330$ & Broadband wireless access \\
\hline 7 & $2330-2335$ & Broadbeand wireless access \\
\hline 8 & $2335-2340$ & Broadband wireless access \\
\hline 9 & $2340-2345$ & Broadiband wireless access \\
\hline 10 & $2345-2350$ & Broadband wireless access \\
\hline 11 & $2350-2355$ & Broadband wireless access \\
\hline 12 & $2355-2360$ & Broadbond wireless access \\
\hline 13 & $2360-2375$ & wIMAX \\
\hline 14 & $2375-2390$ & WIMAX \\
\hline 15 & $2390-2400$ & USO \\
\hline
\end{tabular}

Filter adalah perangkat yang berfungsi untuk melewatkan sinyal-sinyal pada frekuensi tertentu yang diinginkan dan meredam sinyal-sinyal pada daerah frekuensi yang tidak diinginkan. Secara umum, tujuan dari pemfilteran adalah untuk meningkatkan kualitas dari sebuah sinyal atau untuk memisahkan dua atau lebih sinyal yang sebelumnya dikombinasikan dengan tujuan mengefisienkan pemakaian saluran komunikasi yang ada. Pada gambar 1.1 menunjukkan bahwa wimax terdiri dari transmitter Tx dan receiver Rx, setelah sinyal melewati antena(blok channel) pada masing-masing bagian Tx dan Rx terdapat filter bandpass, yang berfungsi menyeleksi frekuensi yang akan dilewatkan ke rangkaian. Filter pada umumnya yang menggunakan komponen elektronika berupa L (lilitan) dan C (kapasitor). Dalam pertimbangan ukuran filter, filter mikrostrip akan menghasilkan ukuran yang lebih kecil dibandingan dengan menggunakan komponen. dengan pertimbangan ukuran filter yang kecil dan kemudahan desain serta fabrikasinya, filter pada penelitian ini akan dirancang dalam bentuk mikrostrip. untuk memperkecil dimensi filter, akan dibuat filter dengan metode hairpin.

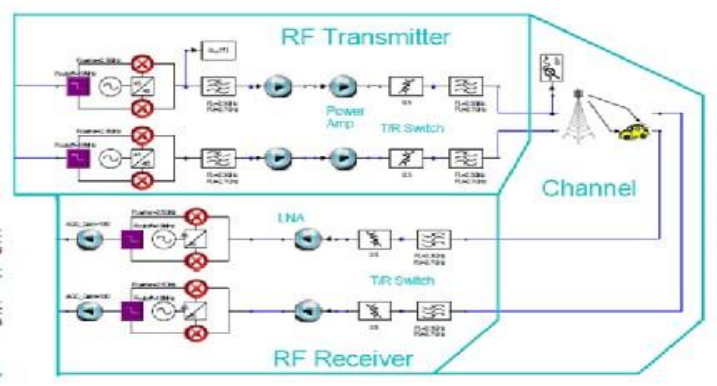

Gambar 1. Blok diagram WIMAX

\subsection{Perumusan Masalah}

Perumusan masalah pada penelitian ini adalah Bagaimana merancang, menguji bandpass filter mikrostrip dengan metode hairpin pada frekuensi $(2,3 \mathrm{GHz}$ sampai dengan $2,4 \mathrm{GHz})$, dengan bandwidth $100 \mathrm{MHz}$ ?

\subsection{Tujuan Penelitian}

Merancang bandpass filter dengan metode hairpin pada frekuensi (2,3 GHz sampai dengan 2,4 GHz) dengan bandwidth 100MHz. Kemudian menguji bandpass filter dengan metode hairpin yang telah dirancang.

\subsection{Hakekat merancang}

Menurut Kennet S. Hurst dalam prinsip- prinsip perancangan teknik, perancangan teknik (2006:4) adalah seluruh aktivitas untuk membangun dan mendefinisikan solusi bagi masalah-masalah yang tidak dapat dipecahkan sebelumnya atau solusi dari berbagai masalah sebelumnya telah dipecahkan namun dengan cara yg berbeda.

\subsection{Hakekat menguji}

Menutut Dendy Sugono (2008:1771) uji adalah percobaan untuk mengetahui kualitas sedangkan menguji (2008:1772) adalah memeriksa sesuatu untuk mengetahui kualitas, kepandaian, dan sebagainya. William Shockley pengukuran adalah perbandingan dengan standar.

\subsection{Filter}

Menurut Dennis Roddy John Coolen (1984:55) dalam telekomunikasi, penyaringan sinyal (filtering) diperlukan untuk 
memisahkan sinyal yang dikehendaki dari sinyal sinyal lain yang dipancarkan dan juga untuk memperkecil pengaruh kebisingan dan interferensi pada sinyal yang dikehendaki tersebut.

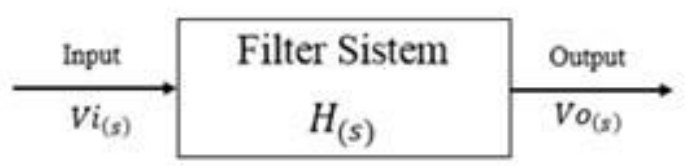

Gambar 2. Diagram Blok Filter Secara Umum

Berdasarkan frekuensi yang dilewatkan, filter dibedakan menjadi empat, yaitu:
A. Lowpass Filter (LFP)
B. Highpass Filter (HPF)
C. Bandpass Filter (BPF)
D. Bandstop Filter (BSF)

\subsection{Bandpass Filter Mikrostrip}

Menurut Jia-Sheng Hong, M. J. Lancaster (2001:29) filter berasal dari fungsi transfer yang dikembangkan menjadi beberapa respon Lowpass filter antara lain Butterworth, Chebycev, Eliptic dan Gausian. Sedangkan Banpass Filter mikrostrip merupakan pengembagan dari respon tersebut
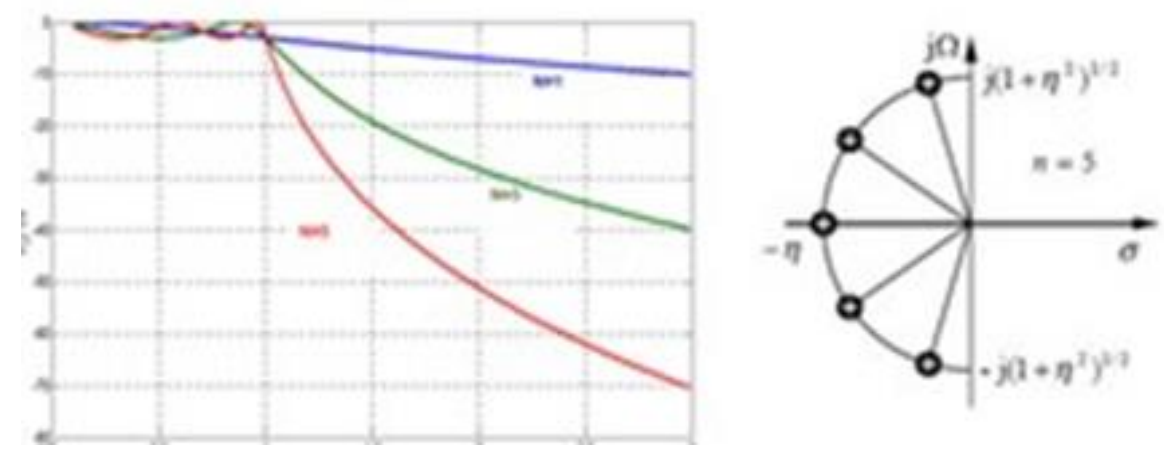

Gambar 3. Respon Lowpass Filter Chebycev

\section{Metodologi Penelitian}

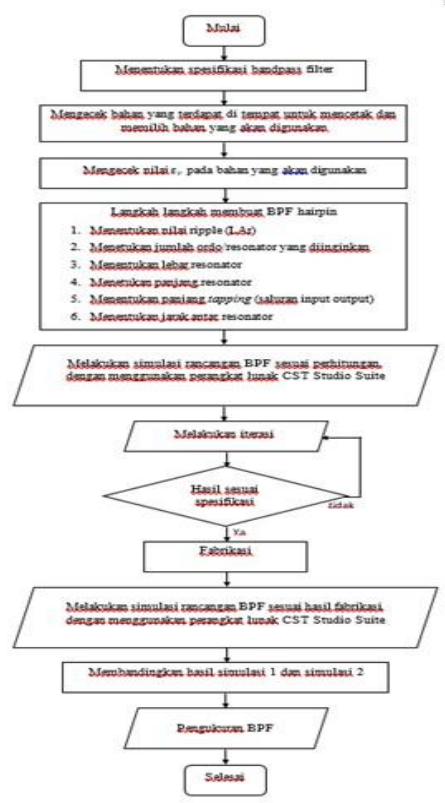

Gambar 4. Diagram Alir permbuatan dan pengukuran bandpass filter hairpin 
Gambar 4 merupakan diagram alir penelitian yang memperlihatkan langkah-langkah penelitian secara rinci. Langkah langkah penelitian berdasarkan diagram alir penelitian

1. Diawali dengan menentukan spesifikasi bandpass filter yaitu menentukan besarnya bandwidth dari filter dan juga frekuensi cut off.

2. Mengecek bahan yang terdapat di tempat mencetak atau PT Spectra. Setelah di cek, dipilihlah bahan yang akan digunakan untuk penelitian, peneliti memilih bahan FR-4.

3. Mengecek nilai $\varepsilon \_r$ (konstanta dielektrik) pada bahan yang sudah dipilih. $\varepsilon \_r$ untuk FR-4 sebesar 4.3.

4. Setelah semua yang dibutuhkan telah dimiliki, langkah berikutnya adalah langkah membuat bandpass filter hairpin berdasarkan persamaan.

a. Menentukan nilai ripple LAr berguna untuk menentukan nilai g saat nanti mendapat ordo, dapat dilihat pada gambar 2.5

b. Menentukan ordo, ordo akan mempengaruhi jumlah resonator yang nanti akan dibuat, ordo didapat dengan memasukkan nilai LAr yang sebelumnya sudah dipilih.

c. Menentukan lebar resonator

d. Menentukan panjang resonator

e. Menentukan panjang tapping atau saluran input output

f. Menentukan jarak antar resonator

5. Setelah didapatkan bentuk dan ukuran dari bandpass filter hairpin, kemudian dilakukan simulasi sesuai dengan data yang telah didapat menggunakan perangkat lunak CST Studi Suite, hingga memunculkan grafik S-Parameter.

6. Seltelah mengetahui hasil dari simulasi, dilakukanlah iterasi karena perhitungan awal hanya sebagai standart dan tidak sesuai dengan spesifikasi yang diinginkan. Iterasi adalah mengubah panjang resonator, lebar resonator, tapping dan juga jarak antar resonator agar grafik yang diinginkan sesuai dengan spesifikasi awal yang diinginkan.

7. Ketika hasil spesifikasi yang diinginkan telah terpenuhi maka desain tersebut selanjutnya difabrikasi, namun jika belum susuai spesifikasi akan terus di iterasi hingga sesuai

8. Fabrikasi merupakan proses mencetak, filter dicetak dengan bantuan PT Spectra.

9. Setelah melakukan fabrikasi, hasil fabrikasi diukur kembali kemudian dibandingkan dengan desainnya bila ada perbedaan ukuran maka, ukuran baru dari hasil fabrikasi akan di simulasikan kembali menggunakan perangkat lunak CST Studio Suite.

10. Hasil dari simulasi pertama dan kedua dibandingakan apakah perbedaan grafiknya jauh atau tidak.

11. Setelah itu dilakukan pengukuran menggunakan network analyzer, kemudian hasilnya dibandingkan dengan kedua simulasi sebelumya

\section{Hasil dan Pembahasan}

3.1 Pengembangan bandpass filter mikrostrip

Metode hairpin merupakan pengembangan bandpass edge coupled seperti pada gambar 5

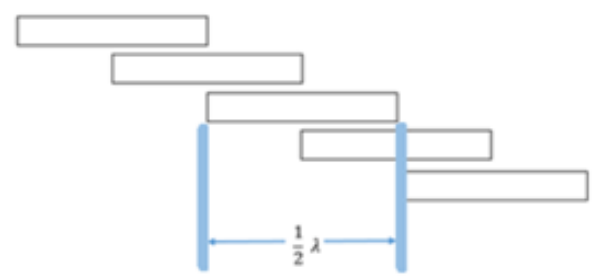

(a)

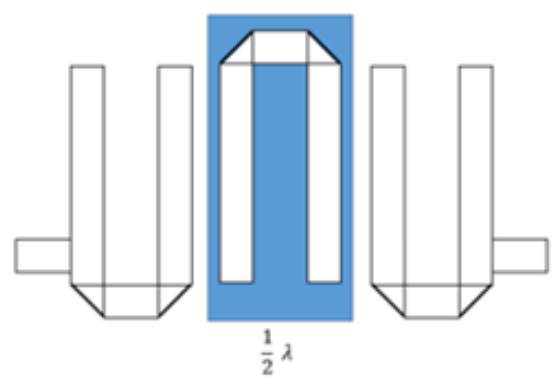

(b)

Gambar 5 . perubahan edge coupled menjadi hairpin. (A) BPF edge coupled. (B) BPF hairpin 
Pada perencanaan Las (peredaman minimum) bernilai 30 dan LAr(ripple pass band) bernilai 0.01

$$
\begin{aligned}
& n \geq \frac{\cosh ^{-1} \sqrt{\frac{10^{0.1 \times 30}-1}{10^{0.1 \times(0.01)}-1}}}{\cosh ^{-1} \times 2.35} \\
& n \geq \frac{7.18}{1.50}=4.78
\end{aligned}
$$

\subsection{Menentukan Ukuran Resonator}

Berdasarkan data yang diperoleh pada bab sebelumnya, maka didapatkan nilai struktur bahan mikrostrip sebagai berikut:

$$
\begin{aligned}
& Z_{0}=50 \Omega \\
& \varepsilon_{r}=4.3 \\
& W_{0}=3.137 \\
& h=1.6
\end{aligned}
$$

Lebar saluran resonator dipegaruhi(W) oleh lebar resonator pada impedansi input( $\left.\mathrm{W}_{0}\right)$. Karena nilai dari $/ \mathrm{h}<2$ maka akan digunakan

$$
\begin{aligned}
& \frac{W_{0}}{h}=\frac{3.137}{1.6}=1.96 \\
& \mathrm{~A}=\frac{\mathrm{z}_{\mathrm{o}}}{60}\left(\frac{\varepsilon_{\mathrm{r}}+1}{2}\right)^{0.5}+\frac{\varepsilon_{\mathrm{r}}-1}{\varepsilon_{\mathrm{r}}+1}\left(0.23 \frac{0.11}{\varepsilon_{\mathrm{r}}}\right)=1.516 \\
& \frac{W}{h}=\frac{8 e^{A}}{e^{2 A}-2}=1.9442 \\
& W=1.9442 \times 1.6=3.1107 \mathrm{~mm}
\end{aligned}
$$

Hairpin memiliki panjang resonator $\lambda / 2$ yang terkopel secara paralel dan bentuk resonatornya seperti huruf ' $U$ ', dimana saluran $\lambda / 4$ dilipat sebesar $\mathrm{L}$ atau $((\lambda / 4)-b)$, maka panjang saluran resonator dapat dihitung dengan persamaan

$$
\begin{aligned}
& \varepsilon_{r e}=\frac{\varepsilon_{r}+1}{2}+\frac{\varepsilon_{r}-1}{2} \frac{1}{\sqrt{\left(1+12 \frac{h}{W}\right)}}=3.2661 \\
& \lambda g=\frac{300}{f c \sqrt{\varepsilon_{r e}}}=70.6380 \\
& L=\frac{1}{2} \lambda g=35.319 \mathrm{~mm}
\end{aligned}
$$

\subsection{Menentukan Nilai Tapping}

Faktor kualitas ditentukan berdasarkanfaktor kualitas pada filter, untuk menentukan letak tapping diperlukan terlebih dahulu nilai dari faktor kualitas dengan persamaan

$Q=\frac{f_{c}}{B W}=23.5$

Setelah mendapatkan nilai faktor kualitas, maka letak tapping dapat ditentukan dengan persamaan

$$
\begin{aligned}
& Z r=\frac{\eta}{2 \pi \mid \sqrt{\varepsilon_{r e}}} \ln \left\{\frac{8 h}{w}+\frac{W}{4 h}\right\}=50.6712 \\
& l=\frac{2 L}{\pi} \sin ^{-1}\left(\sqrt{\frac{\pi}{2} \frac{Z_{0} / Z_{r}}{Q}}\right)=5.8399 \mathrm{~mm}
\end{aligned}
$$

\subsection{Menentukan Jarak Antar Resonato}




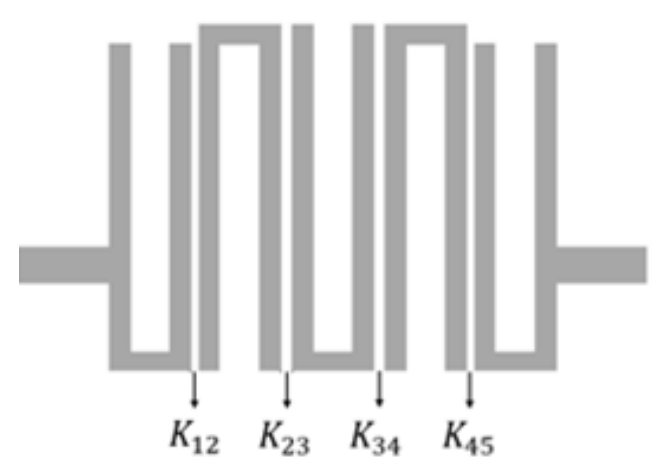

Gambar 6. Letak Koefisien Kopling

$K_{12}=K_{45}=0.0428= \pm 1 \mathrm{~mm}($ space 1$)$

$K_{23}=K_{34}=0.0297= \pm 2 m m($ space 2$)$

Tabel 2 menunjukkan hasil perbandingan ukuran bandpass filter hairpin antara perhitungan dan iterasi.

Tabel 2 Analisis ukuran BPF hairpin

\begin{tabular}{|c|c|c|c|}
\hline panjagy & hail patituronimn] & heil itrengi inulailmm| & hasil tabribsilmm \\
\hline 41 & 16. 15 & 1458 & 14.5 \\
\hline $\mathbf{L}$ & 1043 & 5 & 5 \\
\hline L) & 584 & 5 & 5 \\
\hline 4 & II & 9 & 5 \\
\hline B & 3 & I & 1 \\
\hline 51 & 1 & 0.8 & 0.8 \\
\hline 5 & 2 & 25 & 24 \\
\hline w & 119 & 3 & 3 \\
\hline$w_{i f}$ & 111 & 1 & 1 \\
\hline
\end{tabular}

Tabel 3. menunjukkan perbandingan hasil simulasi dengan fabrikasi. 


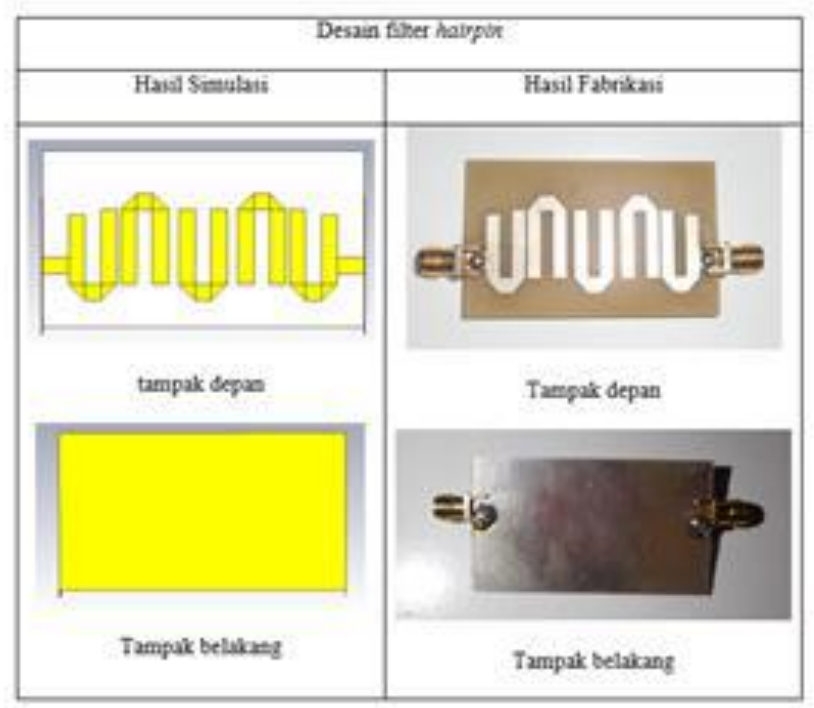

\subsection{Pembahasan Penelitian}

Bandpass filter hairpin merupakan bandpass yang dibangun berdasarkan perubahan bentuk resonator dari bandpass filter edge coupled, resonator yang berbentuk lurus pada bandpass filter edge coupled dibuat menjadi bentuk U pada bandpass filter hairpin. Bandpass filter mikrostrip dibangun berdasar pengembangan lowpass filter mikrostip, atau biasa disebut lowpass prototipe. Lowpass prototipe yang digunakan pada penelitian yaitu Chebycev(memperbolehkan ripple). Ordo pada Chebycev akan mempengaruhi kecuraman pada frekuensi cut off . Jadi semakin besar nilai ordo pada filter akan semakin baik, namun akan menyebabkan bertambahnya resonator yang mengakibatkan bentuk filter semakin besar. Selain ordo banyak hal yang mempengaruhi bandpass filter untuk mendapat hasil yang diinginkan antara lain ukuran resonator dan besar nilai space, pada perhitungan panjang resonator sebesar $16.15 \mathrm{~mm}$ namun tidak mendapatkan hasil yang diinginkan, frekusnsi cut off yang didapat lebih besar dari yang diinginkan, maka pada saat iterasi didapatlah panjang resonator sebesar $14.55 \mathrm{~mm}$. lebar space antar resonator mempengaruhi lebar bandwidth yang didapat, semakin lebar jarak antar resonator bandwidth akan semakin sempit, namun nilai insertion loss akan semakin kecil. Pada tabel 3 akan diperjelas secara rinci nilai insertion loss yang didapat pada simulasi 1, simulasi 2 dan pengukuran ditunjukkan pada gambar

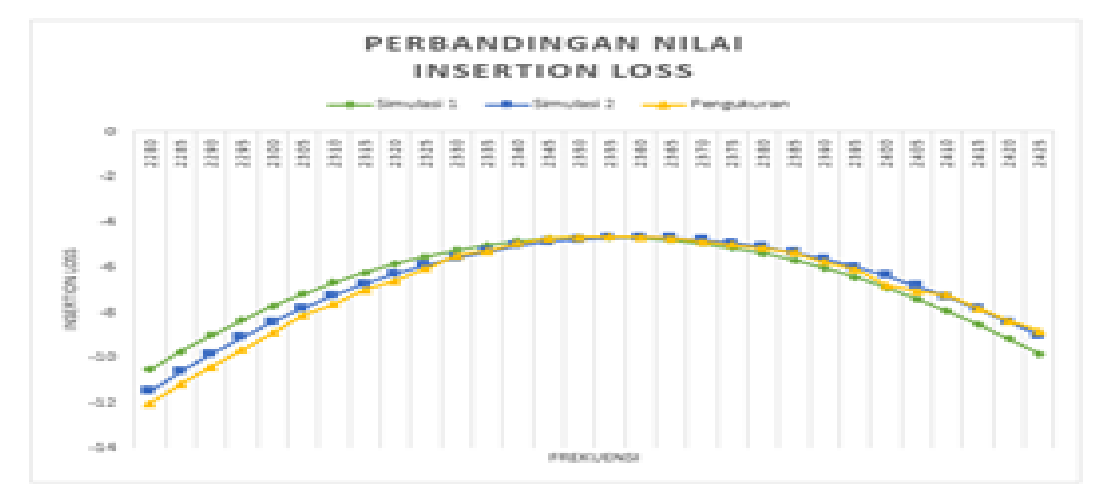

Gambar 7 perbandingan nilai insertion loss dari tabel 4.3

Tabel 3. perbandingan data simulasi denganPengukuran 


\begin{tabular}{|c|c|c|c|c|}
\hline \multirow{2}{*}{ No } & Freizuensi & \multicolumn{3}{|c|}{ Nibi Insention Loss (dB) } \\
\cline { 3 - 5 } & MIIz) & Similasi 1 & Simulasi 2 & Pengikuran \\
\hline 1 & 2280 & -10.52 & -11.5 & -12.03 \\
\hline 2 & 2285 & -9.74 & -10.64 & -11.19 \\
\hline 3 & 2290 & -9.01 & -9.84 & -10.41 \\
\hline 4 & 2295 & -8.34 & -9.11 & -9.66 \\
\hline 5 & 2300 & -7.72 & -8.43 & -8.9 \\
\hline 6 & 2305 & -7.18 & -7.81 & -8.13 \\
\hline 7 & 2310 & -6.68 & -7.26 & -7.65 \\
\hline 8 & 2315 & -6.24 & -6.75 & -7.02 \\
\hline 9 & 2320 & -5.85 & -6.3 & -6.59 \\
\hline 10 & 2325 & -5.53 & -5.92 & -6.07 \\
\hline 11 & 2330 & -5.25 & -5.58 & -5.5 \\
\hline 12 & 2335 & -5.03 & -5.3 & -5.28 \\
\hline 13 & 2340 & -4.85 & -5.06 & -4.95 \\
\hline 14 & 2345 & -4.74 & -4.89 & -4.73 \\
\hline 15 & 2350 & -4.68 & -4.77 & -4.67 \\
\hline 16 & 2355 & -4.67 & -4.7 & -4.66 \\
\hline 17 & 2360 & -4.71 & -4.67 & -4.69 \\
\hline 18 & 2365 & -4.81 & -4.71 & -4.74 \\
\hline 19 & 2370 & -4.95 & -4.8 & -4.88 \\
\hline 20 & 2375 & -5.15 & -4.93 & -5 \\
\hline 21 & 2380 & -5.4 & -5.12 & -5.15 \\
\hline 22 & 2385 & -5.7 & -5.36 & -5.37 \\
\hline 23 & 2390 & -6.05 & -5.65 & -5.77 \\
\hline 24 & 2395 & -6.45 & -5.99 & -6.1 \\
\hline 25 & 2400 & -6.9 & -6.38 & -6.81 \\
\hline 26 & 2405 & -7.4 & -6.82 & -7.06 \\
\hline 27 & 2410 & -7.94 & -7.31 & -7.24 \\
\hline 28 & 2415 & -8.53 & -7.84 & -7.81 \\
\hline 29 & 2420 & -9.16 & -8.42 & -8.38 \\
\hline 30 & 2425 & -9.84 & -9.04 & -8.83 \\
\hline
\end{tabular}

\section{Kesimpulan}

Berdasarkan penelitian yang telah dilakukan, peneliti telah merancang bandpass filter mikrostrip dengan metode hairpin. Bandpass filter hairpin dibuat dengan bantuan perangkat lunak CST Microwave Studio dan dicetak menggukanan bantuan PT. Spectra dengan bahan FR-4 $\left(\varepsilon_{-} \mathrm{r}=4.3\right)$ dan diukur mengguakan network analyzer dengan type agilent N5230C, didapat nilai frekuensi cut off $2.355 \mathrm{GHz}$ dengan bandwidth $106 \mathrm{MHz}$.

\section{DAFTAR PUSTAKA}

1. O. Bishop, , Terj. Dasar Dasar Elektronika (2006)

2. Dennis Roddy dan John Coolen ,Terj. Kamal Idris. Komunikasi Elektronika (1984)

3. Grob, Bernard, Basic Electronics (1987)

4. Hong, Jia-Seng, Lancaster,M.J, Microstrip Filters For RF/Microwave Applications (2001)

5. J. Delap, dkk. Wimax MIMO Circuit And System Design (2007)

6. Kennet S. Hurst, Terj. Refina Indriasari, Prinsip- Prinsip Perancangan Teknik. Penerbit Gelora Aksara Pratama. (2006)

7. Kinayman, Noyan. Modern Microwave Circuit. (Boston: Artech House, Inc., 2005)

8. Mentri komuniasi dan informatika. Peraturan Menkominfo nomor 08/PER/M.KOMINFO/01/2009 tanggal 19 Januari 2009 tentang "Penetapan Pita Frekuensi Radio Untuk Keperluan Layanan Pita Lebar Nirkabel Pada Pita Frekuensi Radio 2.3 GHz".

9. Rafaat R Mansour. High-Q Tunable Dielectric Resonator IEEE microwave magazine. (2009)

10. Sugono, Dendy. Kamus Bahasa Indonesia ( Pusat Bahasa Departemen Pendidikan Nasional, Jakarta, 2008)

11. Supriyanto, Toto. "PERANCANGAN BANDPASS FILTER UNTUK CPE m- WiMAX MENGGUNAKAN FILTER AKTIF MIKROSTRIP HAIRPIN"[tesis]. 2010. FT UI. Depok.

12. Woelfel, Joseph. "The Galileo System: a Rational Alternative to the Dominant Paradigm for Social Science Research". University at Buffalo State University of New York 